\title{
Lifestyle factors as predictors of nonadherence to statin therapy among patients with and without cardiovascular comorbidities
}

\author{
Heli Halava MD, Maarit Jaana Korhonen PhD, Risto Huupponen PhD, Soko Setoguchi MD DrPH, \\ Jaana Pentti BSc, Mika Kivimäki PhD, Jussi Vahtera PhD
}

\begin{abstract}
Background: Easily detectable predictors of nonadherence to long-term drug treatment are lacking. We investigated the association between lifestyle factors and nonadherence to statin therapy among patients with and without cardiovascular comorbidities.
\end{abstract}

Methods: We included 9285 participants from the Finnish Public Sector Study who began statin therapy after completing the survey. We linked their survey data with data in national health registers. We used prescription dispensing data to determine participants' nonadherence to statin therapy during the first year of treatment (defined as $<80 \%$ of days covered by filled prescriptions). We used logistic regression to estimate the association of several lifestyle factors with nonadherence, after adjusting for sex, age and year of statin initiation.

Results: Of the participants without cardiovascular comorbidities ( $n=6458), 3171(49.1 \%)$ were nonadherent with their statin therapy. Obesity (adjusted odds ratio [OR] 0.86, 95\% confidence interval $[\mathrm{Cl}]$ 0.74-0.99), overweight (adjusted OR
0.88, 95\% Cl 0.79-0.98) and former smoking (adjusted OR $0.82,95 \% \mathrm{Cl} 0.74-0.92$ ) predicted a reduced risk of nonadherence in this group after adjustment for sex, age and year of statin initiation. Of the participants with cardiovascular comorbidities ( $n=2827), 1155$ (40.9\%) were nonadherent. In this group, high alcohol consumption (adjusted OR 1.55, 95\% Cl 1.12-2.15), extreme drinking occasions (adjusted OR 1.48, 95\% Cl 1.11-1.97) and a cluster of 3-4 lifestyle risks (adjusted OR 1.61, 95\% Cl 1.15-2.27) predicted increased odds of nonadherence after adjustment for sex, age and year of statin initiation.

Interpretation: People with cardiovascular comorbidities who had risky drinking behaviours or a cluster of lifestyle risks were at increased risk of nonadherence. Among individuals without cardiovascular comorbidities, information on lifestyle factors was unhelpful in identifying those at increased risk of nonadherence; that overweight, obesity and former smoking were predictors of better adherence in this group provides insight into mechanisms of adherence to preventive medication that deserve further study.

\section{$\mathrm{A}$} recent meta-analysis of 44 epidemiologic studies suggested that almost 1 in 10 cardiovascular events can be attributed to medication nonadherence. ${ }^{1}$ For statins, the average prevalence of nonadherence, defined as taking less than $80 \%$ of the prescribed medication, was as high as $46 \% .^{1}$ Multiple patient-, physician- and health system-related factors are known to affect adherence to long-term drug treatment; ${ }^{2}$ however, easily detectable predictors of nonadherence are lacking.

Previous research has consistently shown that patients with a history of cardiovascular events, hypertension or diabetes have better adherence to statin therapy than individuals without these conditions. $^{3-5}$ Patients who adhere to preventive drug treatment are often assumed to also have an otherwise healthier lifestyle than those with poor adherence.$^{6-8}$ Accordingly, some studies have found current smoking status ${ }^{9-14}$ and high alcohol consumption $^{14,15}$ to be associated with nonadherence to lipid-lowering therapy. In a Canadian study involving patients in primary care practices, those who reported regular exercise or a healthy diet had high scores of self-reported statin adherence. ${ }^{16}$ Also, obesity has been linked with good adherence to statin therapy. ${ }^{10,14}$ However, results have been inconsistent, with some studies showing no association between adherence and obesity ${ }^{12,17}$ or physical activity, ${ }^{12,14}$ or even an association between adherence to statins and smoking history. ${ }^{17}$ Furthermore, few studies have provided information on the association between lifestyle factors and statin adherence stratified by cardiovascular comorbidity, which may modify these associations.
Competing interests: None declared for the submitted work. Maarit Jaana Korhonen and Risto Huupponen received grants from the Social Insurance Institution of Finland. Risto Huupponen is a member of the advisory board for Social and Medical Affairs of the Social Insurance Institution of Finland, was a member of a data monitoring and safety committee in a clinical trial sponsored by Orion

Corporation and has assisted Santen Pharmaceutical in

pharmacokinetic calculations.

This article has been peer reviewed.

Correspondence to: Heli Halava,heli.halava@utu.fi

CMAJ 2014. DOI:10.1503 /cmaj.131807 
Dyslipidemia guidelines usually recommend that patient management be focused on total cardiovascular risk, rather than solely on the presence or absence of cardiovascular disease, and emphasize the promotion of a healthy lifestyle to prevent cardiovascular disease. ${ }^{18,19}$ Therefore, a decision to prescribe a statin typically involves assessment of the patient's lifestyle.

We investigated the association between lifestyle factors readily available to prescribers (body mass index [BMI], smoking status, alcohol use and physical activity) and nonadherence to statin therapy separately among patients with and without cardiovascular comorbidities in a large cohort of Finnish employees in the public sector.

\section{Methods}

\section{Study population and design}

We obtained data from the Finnish Public Sector Study, ${ }^{20}$ a prospective study involving all 151901 public sector employees in 10 municipalities and 21 hospitals from 1991 to 2005. The employees cover a wide range of occupational groups, from city mayors to semiskilled cleaners, the largest groups being nurses and teachers.

We initially included the 80459 participants who responded to 1 or more of the surveys in 1997, 2000, 2004 and 2008 (average response rate $70 \%$ ). The questionnaire was designed to collect information on demographic characteristics, lifestyle factors and health status. We linked the survey data to data from national health registers $^{21,22}$ using the participants' unique personal identification numbers. For the final study cohort, we included the 9285 participants who began statin therapy between Jan. 1, 1998, and Dec. 31, 2010, after completing the survey and had not been dispensed statins in the previous 2 years. Follow-up data for adherence to statin therapy were available to Dec. 31, 2011.

\section{Assessment of adherence to statins}

In Finland, statins are available by prescription only. National Health Insurance provides coverage for prescription drugs to all (about 5.4 million) residents living in the community. All reimbursed prescriptions are registered in the Finnish Prescription Register managed by the Social Insurance Institution. ${ }^{21}$ For each drug, the dispensing date, the World Health Organization Anatomic Therapeutic Chemical $\operatorname{code}^{23}$ and the quantity dispensed are recorded.

The outcome of interest was nonadherence to statins (code C10AA) during the first year after initiation. We measured adherence according to the proportion of days covered by prescriptions dispensed during the 365-day period multiplied by 100 , assuming a daily dose of 1 tablet. ${ }^{24}$ We took hospital admissions into account by subtracting the number of inpatient days from the denominator 365. We defined nonadherence as less than $80 \%$ of days covered by filled prescriptions. ${ }^{1}$

\section{Assessment of lifestyle factors}

We assessed lifestyle factors using standard questionnaire measurements. ${ }^{25,26}$ We calculated each participant's BMI using self-reported weight and height and divided the cohort into 3 groups: normal weight (BMI $<25$ ), overweight (BMI 2529.9 ) and obese (BMI $\geq 30$ ). Smoking status was reported as none, former or current. From responses to questions about alcohol use, we determined the number of units of alcohol per week ( 1 unit $=120 \mathrm{~mL}$ of wine, $40 \mathrm{~mL}$ of spirits or $330 \mathrm{~mL}$ of beer). The cut-off for high consumption was 16 drinks per week for women and 24 per week for men. ${ }^{26,27}$ Participants who reported having passed out owing to heavy alcohol consumption at least once during the 12 months before the survey were determined to have extreme drinking occasions. We measured physical activity using the metabolic equivalent of task (MET) index; the sum score of MET hours was used to identify active ( $>4 \mathrm{~h})$, moderate $(2-4 \mathrm{~h})$ or low $(<2 \mathrm{~h})$ physical activity.

In addition, we defined a summary variable reflecting total lifestyle-related cardiovascular risk. ${ }^{25}$ The unhealthiest level of each factor (current smoking, obesity, high alcohol consumption or extreme drinking occasions or both, and low physical activity) was coded as being present or absent. The number of lifestyle risks was grouped into 3 categories ( $0,1-2$ or 3-4 risks).

For participants who responded to more than one survey before starting statin therapy, we selected the most recent survey. The mean lag between the survey and statin initiation ( \pm standard deviation) was $3.4 \pm 2.4$ years.

\section{Other variables}

We considered cardiovascular comorbidities, including cardiovascular diseases and diabetes, as modifiers of the associations between lifestyle factors and nonadherence. We identified these comorbidities using linked data from special reimbursement and hospital discharge registers (entitlements to special reimbursement for drug treatment of chronic hypertension, heart failure, coronary artery disease or diabetes at statin initiation, or hospital admission for these conditions, stroke or arrhythmias during the 36 months before statin initiation) ${ }^{28}$

We treated other comorbidities (e.g., cancer, depression and self-rated health) $)^{1,29-32}$ and sociodemographic characteristics (sex, age, education, 
marital status and residential region) ${ }^{3}$ as potential confounders. Information on cancer diagnosis within 5 years before statin initiation came from the Finnish Cancer Registry. ${ }^{22}$ Prescriptions for antidepressants (code N06A) during the 36 months before statin initiation, captured from the Prescription Register, served as a proxy for depression. We obtained information on self-rated health (classified as suboptimal if average or worse v. not suboptimal if good or very good) and marital status (married or cohabiting v. single, divorced or widowed) from the survey responses. Data on sex, age and residential region came from the employers' administrative registers. Statistics Finland provided information on education that was classified as high (tertiary level), intermediate (upper secondary level) or basic (lower secondary level or less). ${ }^{33}$

\section{Statistical analysis}

We used a logistic regression model to estimate the association between each lifestyle factor and nonadherence. According to the study aim, the main analyses were done separately for respondents with and without cardiovascular comorbidities. Each model was first adjusted for sex, age (24-50, 51-60 and 61-75 yr) and, because of changes in prescribing practices and statin costs over time,${ }^{34}$ the year of statin initiation. The final model was further adjusted for other confounders (education, marital status, residential region, suboptimal self-rated health, use of antidepressants and cancer) and mutually for other lifestyle factors); it included only respondents with complete data on all confounders. The associations between the number of lifestyle risks and nonadherence were analyzed correspondingly.

In a sensitivity analysis, we used a continuous proportion (percentage) of days covered by filled prescriptions as the outcome. We tested the mean difference $(95 \%$ confidence interval $[\mathrm{CI}]$ ) in proportion of days covered across the levels of each lifestyle factor using analysis of variance and adjusting for sex, age and year of statin initiation.

We analyzed data using SAS software, version 9.2 (SAS Institute Inc., Cary, NC).

\section{Ethics approval}

The study was approved by the ethics committee of the Hospital District of Helsinki and Uusimaa.

\section{Results}

From the eligible population of public sector employees, we identified 11949 who began statin therapy between Jan. 1, 1998, and Dec. 31, 2010. Of these, $9285(77.7 \%)$ had completed 1 or more of the surveys. Compared with the respondents, the 2664 nonrespondents were more likely to be male (39.8\% v. $23.8 \%)$, to be less educated (basic education $24.4 \%$ v. $16.5 \%$ ) and to have cardiovascular comorbidities $(36.3 \%$ v. $30.4 \%$ ) at statin initiation; the 2 groups did not differ in mean age $(55.2 \pm 7.8 \mathrm{yr}$ and $55.7 \pm 7.2$ yr, respectively).

Among the respondents, those without cardiovascular comorbidities $(n=6458)$ were more likely to be female, younger, more educated and from southern Finland and less likely to rate their health as suboptimal than those with cardiovascular comorbidities $(n=2827)$ (Table 1). More than half $(53.5 \%)$ of those without cardiovascular comorbidities had 1 or more lifestyle risks:

Table 1: Characteristics of 9285 participants in the Finnish Public Sector Study who began statin therapy after completing the survey

\begin{tabular}{|c|c|c|c|}
\hline \multirow[b]{2}{*}{ Characteristic } & \multicolumn{3}{|c|}{ No. (\%) of participants } \\
\hline & $\begin{array}{c}\text { All } \\
n=9285\end{array}$ & $\begin{array}{c}\text { Without } \\
\text { cardiovascular } \\
\text { comorbidities* } \\
n=6458\end{array}$ & $\begin{array}{c}\text { With } \\
\text { cardiovascular } \\
\text { comorbidities* } \\
n=2827\end{array}$ \\
\hline \multicolumn{4}{|l|}{ Sex } \\
\hline Male & $2211(23.8)$ & $1430(22.1)$ & $781(27.6)$ \\
\hline Female & $7074(76.2)$ & 5028 (77.9) & $2046(72.4)$ \\
\hline \multicolumn{4}{|l|}{ Age group, yr } \\
\hline $24-50$ & $1971(21.2)$ & $1444(22.4)$ & $527(18.6)$ \\
\hline $51-60$ & $4811(51.8)$ & 3344 (51.8) & $1467(51.9)$ \\
\hline $61-75$ & $2503(27.0)$ & $1670(25.9)$ & $833(29.5)$ \\
\hline \multicolumn{4}{|l|}{ Education } \\
\hline High & $4363(47.0)$ & 3185 (49.3) & $1178(41.7)$ \\
\hline Intermediate & $3390(36.5)$ & $2311(35.8)$ & $1079(38.2)$ \\
\hline Basic & $1532(16.5)$ & $962(14.9)$ & $570(20.2)$ \\
\hline Marital status & $n=9144$ & $n=6365$ & $n=2779$ \\
\hline Married & $6976(76.3)$ & $4835(76.0)$ & $2141(77.0)$ \\
\hline Single & $2168(23.7)$ & $1530(24.0)$ & $638(23.0)$ \\
\hline $\begin{array}{l}\text { Residential region } \\
\text { in Finland }\end{array}$ & $n=9260$ & $n=6438$ & $n=2822$ \\
\hline Southern & $5587(60.3)$ & $4014(62.3)$ & $1573(55.7)$ \\
\hline Central & $1947(21.0)$ & 1344 (20.9) & $603(21.4)$ \\
\hline Northern & $1726(18.6)$ & $1080(16.8)$ & $646(22.9)$ \\
\hline $\begin{array}{l}\text { Suboptimal } \\
\text { self-rated health }\end{array}$ & $n=9184$ & $n=6394$ & $n=2790$ \\
\hline No & $5315(57.9)$ & $3983(62.3)$ & $1332(47.7)$ \\
\hline Yes & $3869(42.1)$ & 2411 (37.7) & $1458(52.3)$ \\
\hline Cancer & $n=9285$ & $n=6458$ & $n=2827$ \\
\hline No & $9110(98.1)$ & $6329(98.0)$ & $2781(98.4)$ \\
\hline Yes & 175 (1.9) & $129(2.0)$ & $46(1.6)$ \\
\hline \multicolumn{4}{|c|}{ Use of antidepressants } \\
\hline No & $7547(81.3)$ & $5253(81.3)$ & $2294(81.1)$ \\
\hline Yes & $1738(18.7)$ & 1205 (18.7) & $533(18.9)$ \\
\hline
\end{tabular}


$17.1 \%$ were obese, $16.8 \%$ were current smokers, $8.8 \%$ had high alcohol consumption, 5.9\% had extreme drinking occasions, and $29.8 \%$ had a low level of physical activity (Table 2). Among the respondents with cardiovascular comorbidities, $62.9 \%$ had 1 or more lifestyle risks: $31.1 \%$ were obese, $18.2 \%$ were current smokers, $8.9 \%$ had high alcohol consumption, $8.0 \%$ had extreme drinking occasions, and $35.3 \%$ had a low level of physical activity (Table 3).

Nonadherence to statins during the first year of treatment was slightly more common among the nonrespondents than the respondents $(52.4 \% \mathrm{v}$. $46.7 \%)$. The corresponding figures were $55.0 \%$ and $49.1 \%$ among those without cardiovascular comorbidities at statin initiation, and $47.9 \%$ and $40.9 \%$ among those with such comorbidities. Among all respondents, nonadherence was more common among women, people younger than 61 years, and those who were single (Table 4). No difference in nonadherence was observed among those with complete data compared with those with missing data on at least 1 lifestyle factor (data not shown).

Among the participants without cardiovascular comorbidities, obesity (odds ratio [OR] 0.86 , 95\% CI 0.74-0.99), overweight (OR 0.88, 95\% CI 0.79-0.98) and former smoking (OR 0.82, 95\% CI 0.74-0.92) predicted reduced odds of nonadherence after adjustment for sex, age and year of statin initiation. Further adjustment for other confounders and lifestyle factors had little effect on these associations (Table 2).

Among the participants with cardiovascular comorbidities, high mean alcohol consumption

Table 2: Association between lifestyle factors and nonadherence to statin therapy* among the participants without cardiovascular comorbiditiest

\begin{tabular}{|c|c|c|c|c|c|}
\hline Lifestyle factor & $\begin{array}{c}\text { No. }(\%) \text { of } \\
\text { participants } \\
n=6458\end{array}$ & $\begin{array}{c}\text { No. }(\%) \\
\text { who were } \\
\text { nonadherent } \\
n=3171 \ddagger\end{array}$ & $\begin{array}{l}\text { Unadjusted OR } \\
\qquad(95 \% \mathrm{Cl})\end{array}$ & $\begin{array}{c}\text { Partial } \\
\text { adjustment§ }\end{array}$ & $\begin{array}{c}\text { Full } \\
\text { adjustmentף }\end{array}$ \\
\hline Body mass index & $n=6301$ & & & & \\
\hline$<25$ (ref) & $2550(40.5)$ & $1300(51.0)$ & 1.00 & 1.00 & 1.00 \\
\hline Smoking status & $n=6138$ & & & & \\
\hline None (ref) & $2813(45.8)$ & $1422(50.6)$ & 1.00 & 1.00 & 1.00 \\
\hline Former & $2293(37.4)$ & $1051(45.8)$ & $0.83(0.74-0.93)$ & $0.82(0.74-0.92)$ & $0.83(0.74-0.93)$ \\
\hline Current & $1032(16.8)$ & $534(51.7)$ & $1.05(0.91-1.22)$ & $1.02(0.88-1.18)$ & $0.99(0.85-1.16)$ \\
\hline Extreme drinking occasions & $n=6278$ & & & & \\
\hline No (ref) & $5905(94.1)$ & $2881(48.8)$ & 1.00 & 1.00 & 1.00 \\
\hline Yes & $373(5.9)$ & $193(51.7)$ & $1.10(0.89-1.36)$ & $1.07(0.86-1.33)$ & $1.01(0.81-1.27)$ \\
\hline Physical activity & $n=6274$ & & & & \\
\hline Active (ref) & $2301(36.7)$ & $1124(48.8)$ & 1.00 & 1.00 & 1.00 \\
\hline Moderate & $2105(33.6)$ & $1034(49.1)$ & $1.01(0.90-1.14)$ & $1.02(0.91-1.15)$ & $1.04(0.92-1.18)$ \\
\hline Low & $1868(29.8)$ & $913(48.9)$ & $1.01(0.89-1.14)$ & $1.01(0.90-1.15)$ & $1.03(0.90-1.18)$ \\
\hline No. of lifestyle risks & $n=6439$ & & & & \\
\hline 0 (ref) & $2996(46.5)$ & $1438(48.0)$ & 1.00 & 1.00 & 1.00 \\
\hline
\end{tabular}


(OR 1.55, 95\% CI 1.12-2.15), extreme drinking occasions (OR 1.48, 95\% CI 1.11-1.97) and a cluster of 3-4 lifestyle risks (OR 1.61, 95\% CI 1.15-2.27) predicted increased odds of nonadherence after adjustment for sex, age and initiation year (Table 3). Further adjustment changed these associations slightly: OR $1.58(95 \% \mathrm{CI}$ 1.11-2.25) among those with high alcohol consumption, 1.36 (95\% CI 1.00-1.85) among those with extreme drinking occasions and 1.65 (95\% CI 1.16-2.34) among those with a cluster of 3 4 lifestyle risks (Table 3 ).

In our sensitivity analysis with a continuous adherence measure, obesity, overweight and former smoking were associated with an increase in the mean proportion of days covered by filled prescriptions among those without cardiovascu- lar comorbidities (Appendix 1, available at www .cmaj.ca/lookup/suppl/doi:10.1503/cmaj.131807 /-/DC1). Among those with cardiovascular comorbidities, extreme drinking occasions and a cluster of 3-4 lifestyle risks were associated with a decrease in the mean proportion of days covered.

\section{Interpretation}

In our study involving a large cohort of public sector employees, we found that overweight, obesity and former smoking were associated with reduced odds of nonadherence to statin therapy among individuals without cardiovascular diseases or diabetes. Information on lifestyle factors was unhelpful in identifying those at increased risk of nonadherence in this group. Among par-

Table 3: Association between lifestyle factors and nonadherence to statin therapy* among the participants with cardiovascular comorbiditiest

\begin{tabular}{|c|c|c|c|c|c|}
\hline \multirow[b]{2}{*}{ Lifestyle factor } & \multirow{2}{*}{$\begin{array}{c}\text { No. }(\%) \text { of } \\
\text { participants } \\
n=2827\end{array}$} & \multirow{2}{*}{$\begin{array}{c}\text { No. }(\%) \\
\text { who were } \\
\text { nonadherent } \\
n=1155 \ddagger\end{array}$} & \multirow[b]{2}{*}{$\begin{array}{l}\text { Unadjusted OR } \\
\qquad(95 \% \mathrm{Cl})\end{array}$} & \multicolumn{2}{|c|}{ Adjusted OR (95\% Cl) } \\
\hline & & & & $\begin{array}{c}\text { Partial } \\
\text { adjustment§ }\end{array}$ & $\begin{array}{c}\text { Full } \\
\text { adjustmentๆ }\end{array}$ \\
\hline Body mass index & $n=2730$ & & & & \\
\hline$<25$ (ref) & $736(27.0)$ & $317(43.1)$ & 1.00 & 1.00 & 1.00 \\
\hline $25-29.9$ & $1145(41.9)$ & $451(39.4)$ & $0.87(0.72-1.05)$ & $0.90(0.74-1.09)$ & $0.90(0.74-1.10)$ \\
\hline$\geq 30$ & $849(31.1)$ & $352(41.5)$ & $0.92(0.75-1.13)$ & $0.93(0.76-1.14)$ & $0.97(0.78-1.20)$ \\
\hline Smoking status & $n=2684$ & & & & \\
\hline None (ref) & $1161(43.3)$ & $480(41.3)$ & 1.00 & 1.00 & 1.00 \\
\hline Former & $1034(38.5)$ & $408(39.5)$ & $0.93(0.78-1.10)$ & $0.97(0.82-1.16)$ & $0.95(0.79-1.14)$ \\
\hline Current & $489(18.2)$ & $206(42.1)$ & $1.03(0.83-1.28)$ & $1.08(0.86-1.35)$ & $1.03(0.82-1.31)$ \\
\hline Mean alcohol consumption & $n=2765$ & & & & \\
\hline None (ref) & $433(15.7)$ & $170(39.3)$ & 1.00 & 1.00 & 1.00 \\
\hline Moderate & $2087(75.5)$ & $841(40.3)$ & $1.03(0.83-1.28)$ & $1.10(0.88-1.36)$ & $1.13(0.89-1.42)$ \\
\hline High & $245 \quad(8.9)$ & $115(46.9)$ & $1.35(0.98-1.86)$ & $1.55(1.12-2.15)$ & $1.58(1.11-2.25)$ \\
\hline Extreme drinking occasion & $n=2756$ & & & & \\
\hline No (ref) & $2535(92.0)$ & $1018(40.2)$ & 1.00 & 1.00 & 1.00 \\
\hline Yes & $221 \quad(8.0)$ & $103(46.6)$ & $1.32(1.00-1.75)$ & $1.48(1.11-1.97)$ & $1.36(1.00-1.85)$ \\
\hline Physical activity & $n=2753$ & & & & \\
\hline Active (ref) & $858(31.2)$ & $350(40.8)$ & 1.00 & 1.00 & 1.00 \\
\hline Moderate & $923(33.5)$ & $379(41.1)$ & $1.03(0.85-1.24)$ & $1.02(0.84-1.24)$ & $1.04(0.85-1.27)$ \\
\hline Low & $972(35.3)$ & $393(40.4)$ & $0.99(0.82-1.20)$ & $1.00(0.83-1.21)$ & $0.98(0.80-1.21)$ \\
\hline No. of lifestyle risks & $n=2815$ & & & & \\
\hline 0 (ref) & $1043(37.1)$ & $413(39.6)$ & 1.00 & 1.00 & 1.00 \\
\hline $1-2$ & $1606(57.1)$ & $655(40.8)$ & $1.05(0.90-1.23)$ & $1.05(0.89-1.24)$ & $1.07(0.91-1.27)$ \\
\hline $3-4$ & $166(5.9)$ & $81(48.8)$ & $1.45(1.05-2.02)$ & $1.61(1.15-2.27)$ & $1.65(1.16-2.34)$ \\
\hline \multicolumn{6}{|c|}{$\begin{array}{l}\text { Note: } \mathrm{Cl}=\text { confidence interval, } \mathrm{OR}=\text { odds ratio, ref = reference group. } \\
\text { *Nonadherence }=<80 \% \text { of days covered by filled prescriptions. } \\
\text { tHypertension, heart failure, coronary artery disease, diabetes, stroke or arrhythmias. } \\
\text { tPercentages are based on row totals. } \\
\text { \$Adjusted for sex, age and year of statin initiation. } \\
\text { IAdjusted for factors in the first model plus education, marital status, residential region, suboptimal self-rated health, use of antidepressants, cancer and other lifestyle } \\
\text { factors; } 308 \text { participants were excluded from this model because of missing data on at least } 1 \text { lifestyle factor (except for the no. of lifestyle risks) or covariate. }\end{array}$} \\
\hline
\end{tabular}


ticipants with cardiovascular comorbidities, high alcohol consumption, extreme drinking occasions (passing out because of alcohol use) and having 3-4 lifestyle risks were predictors of nonadherence. Our sensitivity analysis, in which adherence was treated as a continuous measure, supported the robustness of these findings.

The rates of nonadherence in our study are similar to those previously reported from Finland ${ }^{35}$ and elsewhere, ${ }^{1,4}$ including studies involving nonworking and older populations. As expected, ${ }^{3-5}$ patients with a history of cardiovascular disease or diabetes had better adherence to statin therapy than those without these comorbidities. Because of their increased risk of cardiovascular events, ${ }^{19}$ patients with comorbidities likely have a strong perception of the need for statin treatment. ${ }^{36}$ Also, overweight and obese patients have an increased cardiovascular risk ${ }^{19}$ and may also have higher cholesterol levels; thus, a greater clinical need for statin therapy may strengthen their motivation to adhere to treatment. ${ }^{36,37}$ Accordingly, among participants in our study who did not have cardiovascular comorbidities, those who were obese, overweight or former smokers had better adherence than those without these risk factors.

Our findings of associations between nonadherence and high levels of alcohol consumption and clustering of unhealthy lifestyle behaviours among patients with cardiovascular comorbidities support the notion that people who adhere to longterm drug therapy follow a healthier lifestyle. Two previous studies examined the association between alcohol use and adherence to statins and

\begin{tabular}{|c|c|c|c|c|}
\hline Characteristic & $\begin{array}{c}\text { All } \\
n=9285\end{array}$ & $\begin{array}{c}\text { No. }(\%) \text { who were } \\
\text { nonadherentt }\end{array}$ & $\begin{array}{l}\text { Unadjusted } \\
\text { OR }(95 \% \mathrm{Cl})\end{array}$ & $\begin{array}{l}\text { Adjusted } \neq \\
\text { OR }(95 \% \mathrm{Cl})\end{array}$ \\
\hline \multicolumn{5}{|l|}{ Sex } \\
\hline Male (ref) & $2211(23.8)$ & $979(44.3)$ & 1.00 & 1.00 \\
\hline Female & $7074(76.2)$ & $3347(47.3)$ & $1.12(1.02-1.24)$ & $1.16(1.05-1.28)$ \\
\hline \multicolumn{5}{|l|}{ Age group, yr } \\
\hline $24-50$ & $1971(21.2)$ & $1003(50.9)$ & $1.40(1.25-1.59)$ & $1.41(1.25-1.39)$ \\
\hline $51-60$ & $4811(51.8)$ & $2267(47.1)$ & $1.21(1.10-1.34)$ & $1.19(1.07-1.31)$ \\
\hline $61-75$ (ref) & $2503(27.0)$ & $1056(42.2)$ & 1.00 & 1.00 \\
\hline \multicolumn{5}{|l|}{ Education } \\
\hline High (ref) & $4363(47.0)$ & $2083(47.7)$ & 1.00 & 1.00 \\
\hline Intermediate & $3390(36.5)$ & $1561(46.0)$ & $0.94(0.86-1.03)$ & $0.92(0.84-1.01)$ \\
\hline Basic & $1532(16.5)$ & $682(44.5)$ & $0.88(0.78-0.99)$ & $0.90(0.80-1.02)$ \\
\hline Marital status & $n=9144$ & & & \\
\hline Married (ref) & $6976(76.3)$ & $3200(45.9)$ & 1.00 & 1.00 \\
\hline Single & $2168(23.7)$ & $1064(49.1)$ & $1.15(1.05-1.27)$ & $1.15(1.05-1.27)$ \\
\hline Residential region in Finland & $n=9260$ & & & \\
\hline Southern & $5587(60.3)$ & $2571(46.0)$ & $0.97(0.87-1.08)$ & $0.97(0.87-1.08)$ \\
\hline Central & $1947(21.0)$ & $931(47.8)$ & $1.05(0.92-1.20)$ & $1.04(0.91-1.19)$ \\
\hline Northern (ref) & $1726(18.6)$ & $811(47.0)$ & 1.00 & 1.00 \\
\hline Suboptimal self-rated health & $n=9184$ & & & \\
\hline No (ref) & 5315 (57.9) & $2480(46.7)$ & 1.00 & 1.00 \\
\hline Yes & $3869(42.1)$ & 1796 (46.4) & $0.98(0.90-1.07)$ & $0.99(0.91-1.08)$ \\
\hline Cancer & $n=9285$ & & & \\
\hline No (ref) & $9110(98.1)$ & $4260(46.8)$ & 1.00 & 1.00 \\
\hline Yes & $175(1.9)$ & $66(37.7)$ & $0.69(0.51-0.95)$ & $0.73(0.53-1.00)$ \\
\hline \multicolumn{5}{|l|}{ Use of antidepressants } \\
\hline No (ref) & 7547 (81.3) & 3499 (46.4) & 1.00 & 1.00 \\
\hline Yes & $1738(18.7)$ & $827(47.6)$ & $1.06(0.96-1.18)$ & $1.04(0.93-1.16)$ \\
\hline
\end{tabular}


reported findings similar to ours, ${ }^{14,15}$ although they did not separate findings by cardiovascular status. Many potential explanations for this association exist. Heavy drinkers may intentionally avoid taking medication because of potential drug-alcohol interactions, they may unintentionally miss doses or even refills because of intoxication, or they may simply be less concerned about missing doses.

\section{Limitations}

Because of the universal drug reimbursement system in Finland and the availability of statins by prescription only, the Prescription Register provided comprehensive data on filled statin prescriptions. Nevertheless, we were unable to determine if, and to what extent, dispensed medications were not used. In addition, self-reporting tends to underestimate obesity and overweight, ${ }^{38}$ as well as smoking and alcohol use. ${ }^{39,40}$ This underascertainment of nonadherence and lifestyle risks most likely had little effect on our results; if anything, it may have attenuated the observed associations.

People with the unhealthiest lifestyles and highest rates of nonadherence may be less likely to participate in a study than those with a healthier lifestyle. However, in our study, the nonadherence rate among nonrespondents was only 5 percentage points higher than the rate among respondents. Thus, major bias due to selection or missing data seems unlikely.

One reason for the lack of association between lifestyle factors and nonadherence among participants without cardiovascular comorbidity may be that the levels of risk factors observed did not accurately reflect those present at statin initiation: participants who exhibited better adherence may have changed their lifestyle before statin initiation. A Danish study involving people with high cholesterol levels reported that improvement in physical activity and dietary habits predicted initiation of statin therapy during a 5-year follow-up. ${ }^{41}$ In our study, the lag between lifestyle measurement and statin initiation was 3 years on average. We tested whether lag time modified the associations between the lifestyle factors and nonadherence by including an interaction term "lag*lifestyle factor" in each model adjusted by sex, age and year of statin initiation. We found a statistically significant interaction between lag time and extreme drinking occasions in a subpopulation with cardiovascular comorbidities ( $p$ for interaction $=0.04$ ). The association between extreme drinking occasions and nonadherence was stronger among those with more recent responses (data not shown).

We did not assess serum lipid levels or patient's total cardiovascular risk, which may have affected the perceived need for statin therapy and adherence to it.

\section{Conclusion}

The association between lifestyle factors and nonadherence to statin therapy varied according to cardiovascular comorbidity status. People with cardiovascular comorbidities who had risky drinking behaviours or a cluster of lifestyle risks were at increased risk of nonadherence. Among those without cardiovascular comorbidities, information on lifestyle factors was unhelpful in identifying individuals at increased risk of nonadherence. However, the observation that overweight, obesity and former smoking were predictors of better adherence in this group provides insight into mechanisms of adherence to preventive medication that deserve further study.

\section{References}

1. Chowdhury R, Khan H, Heydon E, et al. Adherence to cardiovascular therapy: a meta-analysis of prevalence and clinical consequences. Eur Heart J 2013;34:2940-8.

2. Maningat P, Gordon BR, Breslow JL. How do we improve patient compliance and adherence to long-term statin therapy? Curr Atheroscler Rep 2013;15:291-8.

3. Mann DM, Woodward M, Muntner P, et al. Predictors of nonadherence to statins: a systematic review and meta-analysis. Ann Pharmacother 2010;44:1410-21.

4. Lemstra M, Blackburn D, Crawley A, et al. Proportion and risk indicators of nonadherence to statin therapy: a meta-analysis. Can J Cardiol 2012;28:574-80.

5. Latry P, Molimard M, Begaud B, et al. How reimbursement databases can be used to support drug utilisation studies: example using the main French national health insurance system database. Eur J Clin Pharmacol 2010;66:743-8

6. Dormuth CR, Patrick AR, Shrank WH, et al. Statin adherence and risk of accidents: a cautionary tale. Circulation 2009;119:2051-7.

7. Brookhart MA, Patrick AR, Dormuth C, et al. Adherence to lipid-lowering therapy and the use of preventive health services: an investigation of the healthy user effect. Am J Epidemiol 2007; 166:348-54.

8. Patrick AR, Shrank WH, Glynn RJ, et al. The association between statin use and outcomes potentially attributable to an unhealthy lifestyle in older adults. Value Health 2011;14:513-20.

9. Pfeffer MA, Keech A, Sacks FM, et al. Safety and tolerability of pravastatin in long-term clinical trials: Prospective Pravastatin Pooling (PPP) Project. Circulation 2002;105:2341-6.

10. Kopjar B, Sales AEB, Piñeros SL, et al. Adherence with statin therapy in secondary prevention of coronary heart disease in Veterans Administration male population. Am J Cardiol 2003;92:1106-8.

11. Yang CC, Jick SS, Testa MA. Discontinuation and switching of therapy after initiation of lipid-lowering drugs: the effects of comorbidities and patient characteristics. $\mathrm{Br}$ J Clin Pharmacol 2003;56:84-91.

12. Di Martino M, Degli Esposti L, Ruffo P, et al. Underuse of lipidlowering drugs and factors associated with poor adherence: a real practice analysis in Italy. Eur J Clin Pharmacol 2005;61:225-30.

13. Carey IM, DeWilde S, Shah SM, et al. Statin use after first myocardial infarction in UK men and women from 1997 to 2006: Who started and who continued treatment? Nutr Metab Cardiovasc Dis 2012;22:400-8.

14. Warren JR, Falster MO, Fox D, et al. Factors influencing adherence in long-term use of statins. Pharmacoepidemiol Drug Saf 2013;22:1298-307.

15. Bryson CL, Au DH, Sun $\mathrm{H}$, et al. Alcohol screening scores and medication nonadherence. Ann Intern Med 2008;149:795-804.

16. Natarajan N, Putnam RW, Yip AM, et al. Family practice patients' adherence to statin medications. Can Fam Physician 2007;53:2144-5.

17. Donnelly LA, Doney ASF, Morrist AD, et al. Long-term adherence to statin treatment in diabetes. Diabet Med 2008;25:850-5.

18. Anderson TJ, Gregoire J, Hegele RA, et al. 2012 update of the Canadian Cardiovascular Society guidelines for the diagnosis and treatment of dyslipidemia for the prevention of cardiovascular disease in the adult. Can J Cardiol 2013;29:151-67.

19. Reiner Ž, Catapano AL, De Backer G, et al. ESC/EAS guidelines for the management of dyslipidaemias: the Task Force for the management of dyslipidaemias of the European Society of 
Cardiology (ESC) and the European Atherosclerosis Society (EAS). Eur Heart J 2011;32:1769-818.

20. Vahtera J, Laine S, Virtanen M, et al. Employee control over working times and risk of cause-specific disability pension: the Finnish Public Sector Study. Occup Environ Med 2010;67:479-85.

21. Furu K, Wettermark B, Andersen M, et al. The Nordic countries as a cohort for pharmacoepidemiological research. Basic Clin Pharmacol Toxicol 2010;106:86-94.

22. Teppo L, Pukkala E, Lehtonen M. Data quality and quality control of a population-based cancer registry. Experience in Finland. Acta Oncol 1994;33:365-9.

23. WHO Collaborating Centre for Drug Statistics Methodology. Use of ATC/DDD. Available: www.whocc.no/use_of_atc_ddd/ (accessed 2014 June 2).

24. Lesén E, Sandstrom TZ, Carlsten A, et al. A comparison of two methods for estimating refill adherence to statins in Sweden: the RARE project. Pharmacoepidemiol Drug Saf 2011;20:1073-9.

25. Kivimäki M, Lawlor DA, Davey Smith G, et al. Socioeconomic position, co-occurrence of behavior-related risk factors, and coronary heart disease: the Finnish Public Sector study. Am J Public Health 2007;97:874-9.

26. Halonen JI, Kivimäki M, Virtanen M, et al. Living in proximity of a bar and risky alcohol behaviours: a longitudinal study. Addiction 2013;108:320-8.

27. Lim SS, Vos T, Flaxman AD, et al. A comparative risk assessment of burden of disease and injury attributable to 67 risk factors and risk factor clusters in 21 regions, 1990-2010: a systematic analysis for the Global Burden of Disease Study 2010 [published errata in Lancet 2013;381:1276 and 2013;381:628]. Lancet 2012;380:2224-60.

28. Kivimäki M, Batty GD, Hamer M, et al. Influence of retirement on nonadherence to medication for hypertension and diabetes. CMAJ 2013;185:E784-90.

29. Calip GS, Boudreau DM, Loggers ET. Changes in adherence to statins and subsequent lipid profiles during and following breast cancer treatment. Breast Cancer Res Treat 2013;138:225-33.

30. Sjösten N, Nabi H, Westerlund H, et al. Effect of depression onset on adherence to medication among hypertensive patients: a longitudinal modelling study. J Hypertens 2013;31:1477-84, discussion 1484

31. Grenard JL, Munjas BA, Adams JL, et al. Depression and medication adherence in the treatment of chronic diseases in the United States: a meta-analysis. J Gen Intern Med 2011;26:1175-82.

32. Gadkari AS, McHorney C. Unintentional non-adherence to chronic prescription medications: How unintentional is it really? BMC Health Serv Res 2012;12:98.

33. Official Statistics of Finland (OSF): Official Statistics of Finland [e-publication]. Helsinki (Finland): Advisory Board of OSF. Available: www.stat.fi/meta/svt/index_en.html (accessed 2014 Feb. 4).

34. Helin-Salmivaara A, Korhonen MJ, Alanen T, et al. Impact of out-of-pocket expenses on discontinuation of statin therapy: a cohort study in Finland. J Clin Pharm Ther 2012;37:58-64.

35. Helin-Salmivaara A, Lavikainen PT, Korhonen MJ, et al. Pattern of statin use among 10 cohorts of new users from 1995 to 2004: a register-based nationwide study. Am J Manag Care 2010;16: 116-22.
36. Berglund E, Lytsy P, Westerling R. Adherence to and beliefs in lipid-lowering medical treatments: a structural equation modeling approach including the necessity-concern framework Patient Educ Couns 2013;91:105-12.

37. Mann DM, Allegrante JP, Natarajan S, et al. Predictors of adherence to statins for primary prevention. Cardiovasc Drugs Ther 2007;21:311-6

38. Wills AK, Lawlor DA, Matthews FE, et al. Life course trajectories of systolic blood pressure using longitudinal data from eight UK cohorts. PLoS Med 2011;8:e1000440.

39. Fendrich M, Mackesy-Amiti ME, Johnson TP, et al. Tobaccoreporting validity in an epidemiological drug-use survey. Addict Behav 2005;30:175-81

40. Ekholm O, Strandberg-Larsen K, Gronbaek M. Influence of the recall period on a beverage-specific weekly drinking measure for alcohol intake. Eur J Clin Nutr 2011;65:520-5.

41. Hempler NF, Krasnik A, Pisinger C, et al. The relationship between changes in health behaviour and initiation of lipid-lowering and antihypertensive medications in individuals at high risk of ischaemic heart disease. BMC Public Health 2012;12:626-33.

Affiliations: Departments of Public Health (Halava, Vahtera) and Pharmacology, Drug Development and Therapeutics (Korhonen, Huupponen), University of Turku, and Turku University Hospital (Huupponen Vahtera), Turku, Finland; Duke Clinical Research Institute (Setoguchi), Duke University School of Medicine, Durham, NC; the Finnish Institute of Occupational Health (Pentti, Vahtera), Turku, Finland; the Department of Epidemiology and Public Health (Kivimäki), University College London, London, UK

Contributors: Heli Halava and Maarit Jaana Korhonen provided equal contributions as co-first authors. Heli Halava, Maarit Jaana Korhonen, Mika Kivimäki and Jussi Vahtera were responsible for the study concept and design. Heli Halava and Jaana Pentti analyzed the data. All of the authors interpreted the data, drafted and revised the article, and approved the version submitted for publication. All of the authors had full access to the data (including the statistical reports and tables) and take responsibility for the integrity of the data and the accuracy of the analyses.

Funding: This study was funded by a grant from the Academy of Finland (European Research Area in Ageing 2 [ERA-AGE2] program, grant no. 264944). Soko Setoguchi is supported by a midcareer development award (grant no. K02-HS017731) from the Agency for Healthcare Research and Quality, US Department of Health and Human Services. Mika Kivimäki is supported by the Finnish Work Environment Foundation, the UK Medical Research Council and a professorial fellowship from the UK Economic and Social Research Council. 